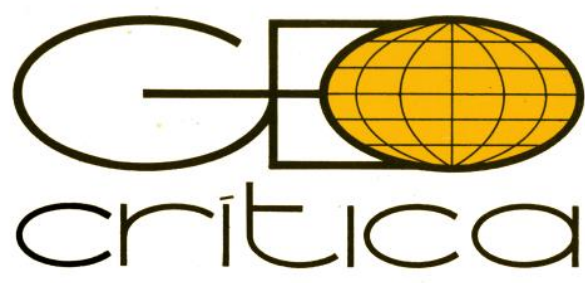

\title{
TRABALHO PRECÁRIO, ESPAÇO PRECÁRIO: AS PLATAFORMAS DIGITAIS DE TRANSPORTE E OS CIRCUITOS DA ECONOMIA URBANA NO BRASIL
}

\author{
Fábio Tozi \\ Universidade Federal de Minas Gerais (UFMG), Brasil \\ fabio.tozi@gmail.com \\ Leandro Ribeiro Duarte \\ Universidade Federal de Minas Gerais (UFMG), Brasil \\ duarterleandrol@gmail.com \\ Gabriel Rocha Castanheira \\ Universidade Estadual de Campinas (Unicamp), Brasil \\ gabrielrcastanheira@gmail.com
}

\section{Trabalho precário, espaço precário: as plataformas digitais de transporte e os circuitos da economia urbana no Brasil (Resumo)}

O artigo analisa o fenômeno da expansão das plataformas digitais de transporte privado por aplicativo no Brasil, particularmente a partir do pioneirismo da Uber. Inicialmente, debate-se a uberização como resultado dos novos nexos históricos entre informação, espaço e trabalho. Em um segundo momento, recupera-se a teoria dos dois circuitos da economia urbana, desenvolvida por Milton Santos (1975) para compreender a ação local das plataformas digitais, com destaque para a pesquisa empírica conduzida em Belo Horizonte (MG). Finalmente, procura-se destacar o papel ativo do espaço nas estratégias das plataformas digitais de transporte, e argumenta-se que elas são dependentes das infraestruturas e usos do território historicamente constituídos. O texto propõe colaborar para o debate acerca da precarização do trabalho nestas plataformas digitais a partir da análise dos espaços precários nos quais ele se realiza.

Palavras-chave: Uberização; Plataformas digitais; Transporte privado por aplicativo; Pobreza urbana; Circuitos da economia urbana. 


\section{Precarious work, precarious space: the ridesharing platforms and the circuits of the urban economy in Brazil (Abstract)}

The article seeks to analyses the expansion of ridesharing platforms in Brazil, especially from Uber's pioneering. Initially, it discusses the uberization process as a result of new historical links between information, space and work. In a second moment, based on the theory of the two circuits of the urban economy developed by Milton Santos (1975), we aim to understand the local action of digital platforms, with emphasis on fieldworks in Belo Horizonte (MG). In doing so, the article proposes a debate on the active role of space in the strategies of digital platforms, once it is argued their dependence on the infrastructures and uses of the territory historically constituted. Finally, the text intends to contribute to the debate on the process of precarious work from the analysis of the precarious spaces in which it takes place.

Keywords: Uberization; Digital platforms; Ridesharing platforms; Urban poverty; Urban economy circuits.

\section{Trabajo precario, espacio precario: las plataformas digitales de transporte y los circuitos de la economía urbana en Brasil (Resumen)}

El artículo analiza el fenómeno de la expansión de las plataformas digitales de transporte privado por aplicación en Brasil, desde el pionerismo de Uber. Inicialmente, se discute la uberización como resultado de nuevas relaciones históricas entre la información, el espacio y el trabajo. En un segundo momento, se recupera la teoría de los dos circuitos de la economía urbana desarrollada por Milton Santos (1975) para comprender la acción local de las plataformas digitales, con énfasis en la investigación empírica realizada en Belo Horizonte (MG). Por último, se destaca el papel activo del espacio en las estrategias de las plataformas digitales y se argumenta que éstas dependen de las infraestructuras y los usos del territorio históricamente constituido. El texto propone colaborar en el debate sobre la precariedad de las relaciones laborales, a partir del análisis de los espacios precarios en los que se desarrolla.

Palabras clave: Uberización; Plataformas digitales; Transporte privado por aplicaciones; Pobreza urbana; Circuitos de la economía urbana.

\section{Introdução}

A informação e a informática têm modificado o conjunto das relações, mesmo que em velocidades distintas nas diferentes formações socioespaciais e nos diversos ramos econômicos. A ascensão da informação como variável-chave do presente altera a relação espaço-tempo ${ }^{1}$, criando um novo período histórico e meio geográfico e alterando a composição orgânica das relações capital-trabalho. Constitui-se, hoje, uma nova esfera técnica da vida e da produção, bem como uma nova psicoesfera ${ }^{2}$, isto é, novos hábitos, valores e comportamentos necessários ao funcionamento eficiente das modernizações.

As corporações são os agentes econômicos que mais se beneficiam do período técnicocientífico-informacional ${ }^{3}$. Dentre elas, cabe destacar aquelas que impulsionam os processos de digitalização da sociedade e do território. Os acrônimos GAFAM e NATU ${ }^{4}$ simbolizam esse

\footnotetext{
${ }^{1}$ Harvey, 1990; Lojkine, 1992; Santos, 1996, 2000.

${ }^{2}$ A psicoesfera, de acordo com Santos (1996), constitui a esfera imaterial do espaço, manifestada em valores, hábitos, crenças, desejos, projetos, ideologias e discursos. Ela se torna fundamental para a compreensão das modernizações na medida em que os objetos técnicos são exigentes de novos hábitos e valores sociais.

${ }^{3}$ Santos, 1994.

${ }^{4}$ Os termos são comuns nos debates francófonos, com forte conotação geopolítica. GAFAM é o acrônimo de Google, Apple, Facebook, Amazon e Microsoft, enquanto NATU representa Netflix, Airbnb, Tesla e Uber.
} 
Trabalho precário, espaço precário: as plataformas digitais de transporte e os circuitos...

grupo particular de empresas, normalmente denominadas plataformas digitais ${ }^{5}$, representantes de uma era de capitalismo de plataforma ${ }^{6}$ ou, mesmo, de um capitalismo de vigilância ${ }^{7}$. A informação foi incorporada como uma variável determinante no processo de acumulação de capital $^{8}$ e, consequentemente, das novas formas de exploração do trabalho ${ }^{9}$. Dessa maneira, a fase atual do capitalismo envolve a dominação dos serviços, da informação e da informatização, simultaneamente. Em contribuição a esse debate, defende-se que o território se torna, também, uma plataforma para as empresas de informação, além de um fator produtivo diferencial. Podese falar, portanto, nas plataformas digitais como "plataformas territoriais", pois de fato elas são altamente dependentes do espaço historicamente construído.

A psicoesfera do atual momento histórico reverbera a ortodoxia neoliberal, multiplicando as nomenclaturas e confundindo seus sentidos. O léxico da chamada sharing economy conduz a uma camuflagem acerca da participação dos distintos sujeitos sociais no sistema econômico e oculta a relação de propriedade dos meios de produção. O trabalhador, renomeado como "empreendedor", "autônomo" ou "microempreendedor", passou a ser considerado um consumidor dos serviços de intermediação digital, como se discutirá adiante a partir do caso dos "motoristas-parceiros" (partner-drivers) que trabalham com aplicativos privados de transporte.

Normalmente traduzidas como "flexibilização" e "desregulamentação", as leis trabalhistas têm revelado a nova face do Estado brasileiro desde os anos 1990, com a expansão progressiva da etapa neoliberal do capitalismo ${ }^{10}$. Nesse sentido, a classe trabalhadora foi sendo cada vez mais impelida para a precarização e a informalidade, sob a forma de subcontratações, terceirizações, "pejotização ${ }^{11 ", ~ t r a b a l h o s ~ t e m p o r a ́ r i o s ~ e ~ s i m i l a r e s, ~ m e s m o ~ q u e ~ p a r a ~ u m a ~ p a r c e l a ~ i m p o r t a n t e ~ d o s ~}$ trabalhadores a formalização nunca tenha sido uma possibilidade tangível. A combinação entre informática, informação e precarização do trabalho tem levado diversos autores a falar em um processo de $u$ berização do trabalho ${ }^{12}$, graças à visibilidade da corporação estadunidense Uber ${ }^{13}$ nesse processo, que, todavia, não se resume a ela.

A uberização, contudo, não significa o abandono da propriedade privada e da hierarquia das decisões nas relações de trabalho. Fato novo, o algoritmo realiza uma mediação técnica entre os trabalhadores, pulverizados remotamente, e a corporação, levando a um novo patamar as formas de controle, mesmo que os elementos tradicionais das relações trabalhistas, definidos pela CLT (Consolidação das Leis Trabalhistas, especialmente artigos $2^{\circ}$ e $3^{\circ}$ ) não tenham sido suprimidos: a pessoalidade, a não eventualidade e a subordinação do trabalhador em relação às decisões da empresa ${ }^{14}$.

\footnotetext{
${ }^{5}$ Slee, 2015; Stone, 2017.

${ }^{6}$ Srnicek, 2016.

${ }^{7}$ Zuboff, 2015.

${ }^{8}$ Hardt \& Negri, 2000, p. 281.

${ }^{9}$ Dantas, 1999.

${ }^{10}$ Antunes, 2018.

${ }^{11}$ Em referência à transformação do empregado em Pessoa Jurídica (PJ), de onde deriva o termo "pejotização".

${ }^{12}$ Abílio, 2017; Pochmann, 2016; Rosenblat, 2018; Tozi, 2017a, 2018.

${ }^{13}$ A Uber foi fundada em 2009 em São Francisco (EUA) e chegou ao Brasil em 2014, a partir do Rio de Janeiro. Em dezembro de 2018, a empresa operava em mais de 700 cidades em 63 países, realizando 14 milhões de viagens por dia, sendo 74\% delas fora dos Estados Unidos.

${ }^{14}$ Castanheira, 2019.
} 
Nessa direção, este texto busca colaborar na compreensão desse movimento a partir de uma contribuição geográfica, haja vista que as relações de trabalho são sempre relativas a um meio geográfico concreto, isto é, há sempre uma condição estrutural e normativa intrinsecamente espacial. Especificamente, dedica-se às relações de trabalho que se estabelecem com a chegada e a banalização do transporte privado por aplicativo, ramo econômico no qual a Uber foi pioneira. Empiricamente, a pesquisa centrou-se na cidade Belo Horizonte (estado de Minas Gerais, Brasil) e sua respectiva Região Metropolitana, buscando inserir esse debate nas transformações que ocorrem na totalidade da formação socioespacial brasileira.

\section{O controle algorítmico do trabalho e do território pelas plataformas de transporte}

Apoiando-se em pesquisas com "motoristas-parceiros", defende-se que as plataformas digitais, a despeito de sua aparência virtual, são dependentes das externalidades essenciais (a cidade, os condutores e seus veículos) para a extração de renda pela venda de seu serviço (transporte). Apoiam-se na propriedade de um capital fixo de novo tipo, como as plataformas, os aplicativos e os algoritmos. As informações estratégicas são fundamentais à produtividade dessas empresas pois são utilizadas para calcular a oferta e a demanda no território em tempo real, prevenir riscos, antecipar lucros, sugerir comportamentos e modificar a prestação de serviços.

Particularmente, a Uber, mediada por esses meios informáticos de produção, possui elevada capacidade de adaptação às diversas peculiaridades das formações socioespaciais onde atua, sem que isso comprometa sua centralização na hierarquia de comando. Nota-se, por exemplo, que a empresa não aceita o pagamento em dinheiro em diversos países europeus. Em contrapartida, em países mais pobres, como o Brasil, a Uber necessita fazê-lo, pois, dessa maneira, consegue atuar nas áreas empobrecidas do território. Com essa "tropicalização", a empresa tem sido eficiente em abranger uma parcela da população que não possui acesso ao sistema bancário e às formas eletrônicas de pagamento.

Em relação ao planejamento da circulação de pessoas pelo território, as plataformas digitais de transporte são capazes de redesenhar, à distância, os deslocamentos nas cidades brasileiras. Duas ações destacam-se nesse sentido: i) a seleção das áreas de atuação pelos critérios de demanda, renda e concentração de redes de transporte; ii) a exclusão de áreas classificadas como "perigosas" por meio do GeoFencing ou "cercamento geográfico".

O GeoFencing é a definição, via GPS, de áreas nas quais os passageiros não podem solicitar viagens. Em geral, o motivo para o cercamento geográfico é a insegurança dos condutores. Essa prática, por outro lado, tem deixado zonas populares e periféricas fora da área de cobertura das empresas, que assumem, assim, um papel político na organização da mobilidade no território (Figura 1). O cercamento também é utilizado em hubs de demanda, como o Aeroporto Internacional de Confins, localizado na Região Metropolitana de Belo Horizonte. Neste caso particular, o GeoFencing visa organizar a criação de uma "fila virtual" de espera para os motoristas da Uber que chegam ao Aeroporto e aguardam, durante horas, uma corrida de retorno, como se discutirá mais detalhadamente adiante.

Ao mesmo tempo, as empresas, por meio das "tarifas dinâmicas" georreferenciadas, direcionam os motoristas para as áreas de alta concentração de demanda na Região Metropolitana, em especial a área Centro-Sul do município de Belo Horizonte (Figura 1). A área é importante para as empresas, pois concentra serviços públicos (judiciário, legislativo e executivo) e privados, 
Trabalho precário, espaço precário: as plataformas digitais de transporte e os circuitos...

comércios, instituições de ensino, centros de lazer e cultura que permitem uma valorização desigual do território por meio tarifas dinâmicas. Dessa forma, o preço de cada viagem é acrescido por um valor que depende da demanda georreferenciada.

Figura 1. Cercamento geográfico e tarifa dinâmica georreferenciada em Belo Horizonte
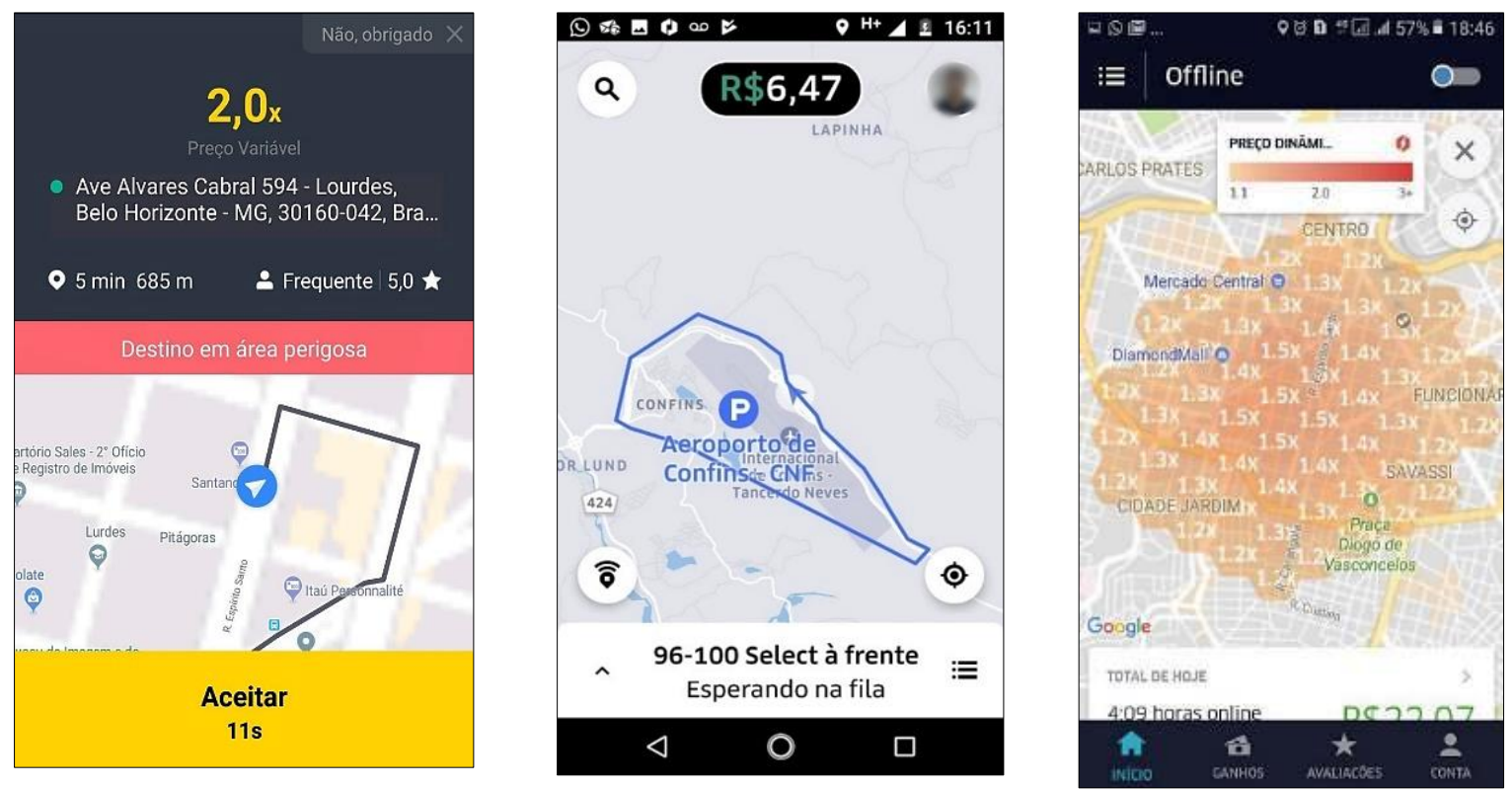

Fonte: Capturas de tela de motoristas entrevistados em 24/09/2019 e 16/10/2018, respectivamente.

Nota: Da esquerda para a direita: indicação de destino em área perigosa pela empresa 99 (o destino era um conjunto de habitação social); "cercamento geográfico" (GeoFencing) do Aeroporto de Confins, pela Uber; tarifa dinâmica da Uber para a região Centro-Sul de Belo Horizonte.

Ao possuir o maior número de motoristas cadastrados em sua plataforma, a Uber controla, em tempo real, informações sobre os deslocamentos no território. Esses bancos de dados são utilizados para uma maior subordinação dos condutores em relação à empresa ${ }^{15}$. Os motoristas afirmaram ${ }^{16}$ que a Uber envia um relatório semanal com questionamentos sobre as viagens que realizaram. Caso alguma viagem tenha sido realizada em um trajeto ou tempo diferentes do que havia sido previsto pela plataforma, o motorista é notificado. A autonomia do motorista, na prática, não é tolerada, mesmo que a empresa insista em considerá-lo um trabalhador autônomo.

Por meio do acesso ao giroscópio e ao acelerômetro dos smartphones pessoais, a empresa envia alertas aos motoristas por suas condutas consideradas inadequadas por ela, como velocidade elevada, acelerações e freadas bruscas (Figura 2). Logo, a Uber, através do smartphone, exerce a função de um supervisor full-time do trabalho de milhares de motoristas dispersos. A "Taxa de cancelamento" de viagens (Figura 2) indica outra forma de avaliação do trabalhador pela empresa, que, ainda, informa que a "confiança e eficiência da plataforma" dependem do

\footnotetext{
${ }^{15}$ Oitaven, Carelli e Casagrande, 2018; Castanheira, 2019; Castanheira \& Duarte, 2019; Duarte, 2019; Tozi, 2017a, 2018; Tozi \& Duarte, 2018.

16 As entrevistas, abertas, realizaram-se sistematicamente desde março de 2017 em viagens solicitadas aleatoriamente pelas plataformas de transporte e ocorreram em Belo Horizonte, com destaque para a região CentroSul. Abordagens em campo foram feitas em eventos pontuais, como os protestos e manifestações de motoristas. Visitas a campo foram acompanhadas por motoristas com os quais se estabeleceu contatos frequentes, especialmente as idas ao Aeroporto Internacional de Confins. Importante mencionar que não obtivemos respostas às tentativas de contato com as empresas.
} 
motorista, que deve "manter a taxa de cancelamento reduzida". Essa vigilância corporativa digital cria um estresse constante sobre os condutores, conforme os relatos obtidos em entrevistas. O "motorista-parceiro", por sua vez, possui autonomia mínima no que diz respeito à escolha da origem e do destino de cada viagem, da oferta de veículos e da demanda de viagens no território, do mercado e do próprio aplicativo, revelando que a despeito de negá-lo sistematicamente, a empresa decide sobre a organização do trabalho.

Figura 2. Controle algoritmo do estilo de direção e da taxa de cancelamento pela Uber
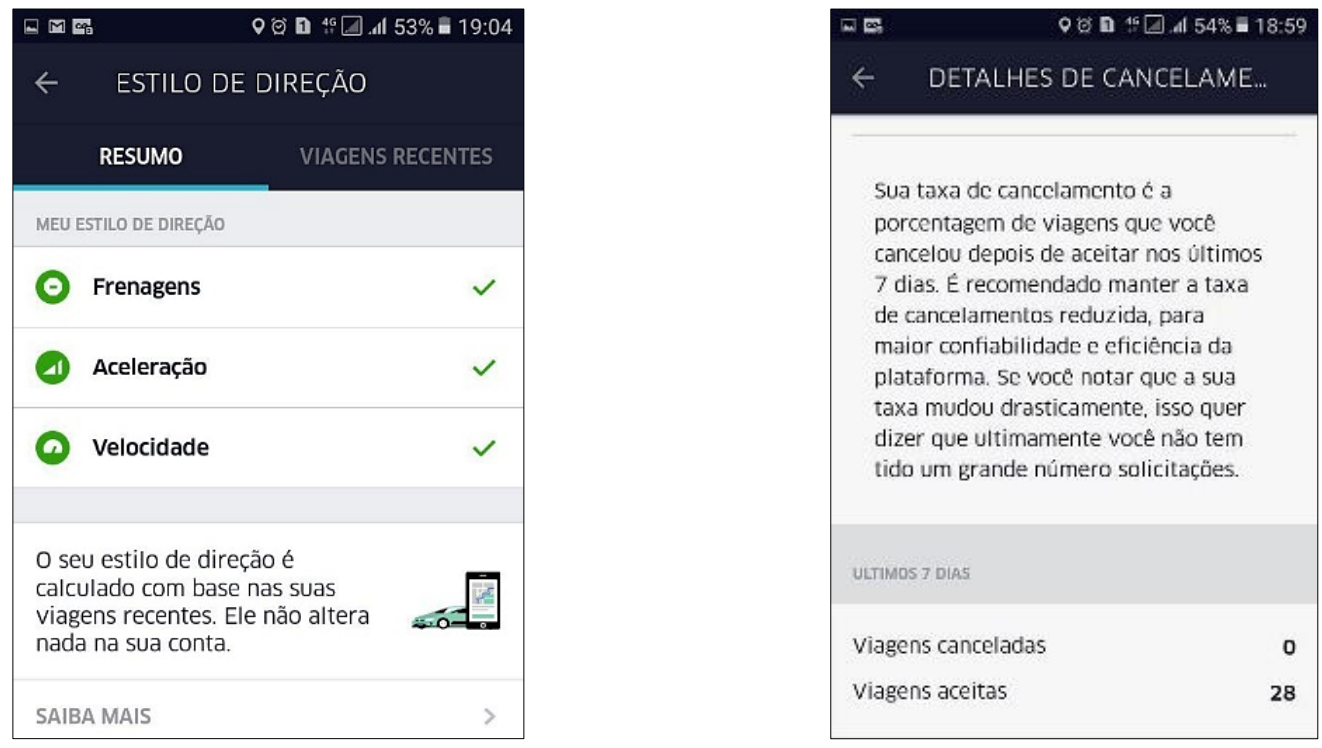

Fonte: Capturas de tela de motoristas entrevistados, em 29/08/2017.

No caminho inverso, é o uso da informação extraída dos lugares, que, sistematizada, torna-se um recurso estratégico das plataformas de transporte por aplicativo e da Uber, em particular. Esse movimento implica na sua adaptação às configurações territoriais presentes em cada país, e, sobretudo, às dinâmicas das suas economias urbanas, atualizando a importância das cidades como centros da prestação de serviços no período informacional. Nesse sentido, voltamos à teoria dos circuitos da economia urbana, para aprofundar o debate com categorias que nos permitem avançar na relação entre economia e espaço no Brasil.

\section{A teoria dos dois circuitos da economia urbana e as empresas de transporte por aplicativo no Brasil}

Acredita-se que a ação de uma corporação global como a Uber no Brasil, com suas regiões e cidades, pode se beneficiar de diversos elementos teórico-metodológicos propostos na teoria dos dois circuitos da economia urbana desenvolvida por Milton Santos ${ }^{17}$, desde que atualizados. Para o autor, mesmo que as cidades sejam formadas por infinitos subsistemas econômicos, pode-se, analiticamente, definir-se a existência de um circuito superior e um circuito inferior. O primeiro é tendencialmente global e inclui as atividades econômicas de capital intensivo, alto grau de organização e tecnologia avançada; o circuito inferior é composto por atividades econômicas de escala local ou regional, pouco capitalizadas e destituídas de elementos tecnológicos e organizacionais sofisticados.

\footnotetext{
${ }^{17}$ Santos, 1975.
} 
Trabalho precário, espaço precário: as plataformas digitais de transporte e os circuitos...

Os dois circuitos são singulares e, ao mesmo tempo, dependentes um do outro; são divergentes nas suas características constitutivas, mas complementares em suas relações. Fugindo às análises dualistas acerca da relação entre espaço e economia, a teoria procura apreender a cidade como uma totalidade em movimento. Novos nexos tecnológicos e informacionais se estabelecem entre os circuitos econômicos e atualizam a dependência do circuito inferior em relação ao circuito superior ${ }^{18}$.

No circuito inferior, as atividades e os agentes possuem formas particulares de organização e de trabalho. As necessidades ligadas à sobrevivência e a criação de oportunidades de geração de renda para uma multidão de trabalhadores pouco qualificados leva a adaptações constantes às condições conjunturais. Por isso, a precarização do trabalho em países de inserção periférica no capitalismo, como o Brasil, não se resume à questão da formalidade-informalidade, assumindo formas de organização mais complexas. Historicamente, a formalização das relações de trabalho nunca abarcou uma parcela significativa das atividades e dos agentes econômicos, especialmente aqueles mais vinculados ao circuito inferior da economia urbana.

Entretanto, a definição analítica do que seja superior ou inferior é tributável de cada momento histórico, de cada ramo econômico e de cada formação socioespacial. Propõe-se, nessa direção, pensar a contribuição dessa teoria incorporando as empresas de transporte por aplicativos como novos agentes que redefinem o limite superior dentro do ramo de transportes, apesar de sua existência recente. A Uber e suas concorrentes 99 (chinesa ${ }^{19}$ ) e Cabify (espanhola) situam-se no circuito superior da economia se considerarmos sua presença global, sua capitalização, organização burocrática, alta densidade tecnológica e o uso de informações estratégicas ${ }^{20}$.

A chegada de Uber, Cabify e 99 em países periféricos representou a sua consolidação como agentes globais e revela um processo de oligopolização deste ramo. Nas cidades onde se instalaram, essas empresas causaram "curtos-circuitos" nos circuitos inferiores, como se observou a partir dos serviços de táxi, transportes públicos e privados, motofretistas e demais sistemas de entrega localmente geridos. No Brasil, esse processo coincide com o aumento sustentável da taxa de desemprego, que passa de $7.2 \%$ em 2013 para $11.9 \%$ em $2020^{21}$.

A instalação destes novos agentes globais nas cidades brasileiras abarcou o desenvolvimento de um "enxame de atividades de sobrevivência ${ }^{22 ", ~ f o r m a d o ~ p e l a ~ m u l t i d a ̃ o ~ d e ~ d e s e m p r e g a d o s ~}$ que passou a desenvolver atividades diretamente vinculadas às plataformas, independentemente da sua formalização. Esses trabalhadores assumiram longas jornadas de trabalho com submissão algorítmica e baixa remuneração, tornando-se motoristas e, em um segundo momento, entregadores. Logo, novos nexos informacionais, digitais e financeiros se estabelecem entre esses trabalhadores pauperizados e o circuito superior da economia.

\footnotetext{
${ }^{18}$ Cataia \& Silva, 2013; Montenegro, 2012; Silveira, 2013; Tozi, 2017 b.

${ }^{19}$ A startup brasileira 99Pop foi comprada pela chinesa Didi Chuxing em 2018.

${ }^{20}$ Adota-se a diferenciação entre informações banais e informações estratégicas conforme Silva, 2001, p. 112.

${ }^{21}$ Segundo o Instituto Brasileiro de Geografia e Estatística (IBGE), a partir da Pesquisa Nacional por Amostra de Domicílios Contínua. A média anual de desocupados no país, em 2013, era 7.2\% e, em 2018, 12.2\%. O recorde da série histórica ocorreu durante o primeiro trimestre de 2017 , com $13.7 \%$ da população economicamente ativa desocupada. Além disso, cresce a taxa de subutilização da força de trabalho. Disponível em: <https://www.ibge.gov.br/estatisticas/sociais/trabalho/17270-pnad-continua.html?=\&t=series-historicas > e <https://www.ibge.gov.br/explica/desemprego.php>. Acessos em junho de 2020.

${ }^{22}$ Silveira, 2013, p. 67.
} 
Ao mesmo tempo, surgem outras atividades do circuito inferior indiretamente dependentes das plataformas. São atividades mais comunicacionais do que informacionais e nas quais a circulação local de dinheiro, geralmente em espécie, é essencial. Entre essas atividades, podemos citar os lava jatos, oficinas de conserto e restaurantes e lanchonetes de bairro ${ }^{23}$. $\mathrm{O}$ cotidiano econômico dos motoristas divide-se entre a Uber, cuja sede localiza-se em São Francisco (EUA), e os comércios e serviços locais.

O número de empregados diretos da Uber permite verificar a relevância do trabalho informacional para as atividades de comando da empresa (Quadro 1). A metade deles (11.860) se concentra em atividades de Operação e suporte, seguidos por P\&D, Administrativo e Vendas e marketing, ou seja, atividades com elevada qualificação e salários. Apenas a união histórica entre GPS, informação e informática permitiria que uma empresa com 22.263 funcionários controlasse 3,9 milhões de motoristas em 14 países. Assim, a tecnociência é uma variável concreta de sua estratégia global, ao mesmo tempo em que permite uma rápida adaptação às diferentes situações nacionais e locais, criando um sistema just-in-time e just-in-place da prestação de serviço e da extração de renda.

A quantidade de empregados em "vendas e marketing" (1.951) revela a importância dessa atividade para a Uber. Os gastos desta corporação nesse segmento estão entre os mais significativos, atingindo USD 3,151 bilhões em 2018, o que representa um crescimento de $25 \%$ em relação ao ano de $2017^{24}$. Além de atrair novos consumidores, a propaganda difunde a ideia de uma empresa ao mesmo tempo moderna e indispensável, reforçando a consolidação de uma nova psicoesfera da mobilidade no Brasil.

Quadro 1. Número de trabalhadores contratados pela Uber no mundo (12/2018)

\begin{tabular}{|l|l|}
\hline Atividade & Número de empregados \\
\hline Operação e suporte & 11.860 \\
\hline Pesquisa e Desenvolvimento (P\&D) & 5.459 \\
\hline Administrativo & 2.993 \\
\hline Vendas e marketing. & 1.951 \\
\hline Total de empregados & 22.263 \\
\hline Motoristas cadastrados & 3,9 milhões \\
\hline
\end{tabular}

Fonte: Uber Technologies, Inc., 2019, p. 186. Organização própria.

Apesar de sua atividade visível ser o transporte de passageiros e objetos a empresa apoia-se em capital intensivo para assegurar a baixa empregabilidade direta. A forma tecnológica do capitalintensivo é, portanto, fator central para o circuito superior, enquanto para o circuito inferior o trabalho-intensivo é a regra, fato que se revela nas longas jornadas de motoristas, que normalmente superam as 12 horas diárias, ainda que parte substantiva desse tempo não seja produtivo, isto é, seja dispendido na espera da prestação do serviço ${ }^{25}$.

O caráter dialético entre os dois circuitos da economia urbana também permite atualizar os nexos informacionais entre eles, particularmente a partir da banalização de smartphones, redes de Internet e tecnologia de geolocalização, mas, também, pelas finanças. Cada vez mais, os cartões de crédito e outros serviços financeiros digitais - fundamentais para a ação eficaz das

\footnotetext{
${ }^{23}$ A pesquisa de Bozzi (2019) analisa o cotidiano de jovens trabalhadores de um serviço de lava jato em Betim (município da Região Metropolitana de Belo Horizonte), pelo qual circulam motoristas de aplicativos.

${ }^{24}$ Uber Technologies, Inc., 2019, p. 116.

${ }^{25}$ As entrevistas que realizamos com motoristas nos últimos três anos revelam, ainda, que as jornadas de trabalho aumentaram, nesse período.
} 
Trabalho precário, espaço precário: as plataformas digitais de transporte e os circuitos...

empresas de transporte por aplicativo -, se fazem presentes entre as camadas mais pobres da população. Logo, esse processo apoia uma nova forma de drenagem ou "vampirização ${ }^{26 "}$ do dinheiro do circuito inferior, cuja circulação era mais local ou regional quando consideramos os modais de transporte "tradicionais", como ônibus, metrô e, especialmente, táxis e mototáxis. Com os aplicativos, uma parcela entre $20 \%$ e $40 \%$ do preço final de cada viagem é apropriada por uma corporação exógena ao lugar e ao próprio país.

Além disso, a transferência de custos fixos aos trabalhadores permite que as empresas ofereçam baixos preços nas corridas, o que implica que a parcela que cabe aos motoristas tende constantemente à redução. Trata-se, portanto, de um preço artificial, pois não incorpora o desgaste e manutenção dos instrumentos de trabalho (smartphone, carro, combustível, revisões e consertos), que são absorvidos pelos trabalhadores. Essas práticas, que poderiam configurar dumping ou concorrência desleal, são camufladas na pscicoesfera da inovação e da modernidade que as empresas invocam para si e na necessidade de sobrevivência dos trabalhadores, a despeito deles se considerarem ou não autônomos e empreendedores.

Para além da "vampiração" da renda local, a drenagem de outros recursos é imprescindível para o funcionamento das plataformas digitais. As áreas de atuação fornecem, involuntariamente, um insumo informacional que transforma motoristas e passageiros, com seus veículos e smartphones, em recenseadores das dinâmicas dos locais que frequentam ${ }^{27}$. Essas informações são sistematizadas pelos centros de comando das empresas e ganham novo sentido e valor, tornando-se informação estratégica. Essa, por sua vez, retorna ao lugar de origem, verticalmente, como normas de funcionamento e de controle, preços, taxas e tarifas dinâmicas que permitem um uso corporativo do território cada mais rentável.

\section{Táticas de adaptação dos motoristas em meio à precarização nas plataformas de transporte}

Como primeira grande plataforma de transporte no Brasil, a Uber criou um novo hábito no ato de deslocar-se, fato que é notável em um país onde o táxi era considerado um serviço caro e eventual. Consequentemente, os consumidores experimentaram novas relações espaçotemporais de deslocamento, o que impulsionou a demanda por mais viagens por aplicativos. Enquanto isso, o serviço de táxi passou a ser considerado obsoleto, pouco confiável e caro e os transportes públicos, cujas redes sempre foram precárias, são esvaziados. Com essa nova psicoesfera que define o deslocar-se "moderno", a empresa se protege, ainda, contra as tentativas de regulação estatal. Não por acaso, as despesas com transporte ultrapassaram as despesas alimentares nos orçamentos das famílias brasileiras ${ }^{28}$.

\footnotetext{
${ }^{26}$ A“vampirização" é uma metáfora para a extração ou drenagem dos recursos financeiros do circuito inferior para o circuito superior da economia, conforme Santos (1975).

${ }^{27}$ Como observam Cardon \& Casilli (2015), o trabalhador digital aparenta ser invisível, mas deixa infinitos rastros digitais.

${ }^{28}$ De acordo com o IBGE, o segundo maior gasto do orçamento familiar, em 2019, após "habitação", foi com "transportes" (18,1\%), superando, pela primeira vez, os gatos com "alimentação" (17,5\%). Disponível em: <https://biblioteca.ibge.gov.br/visualizacao/livros/liv101670.pdf> Acesso em: 6 de junho de 2020.
} 
Com o objetivo de sistematizar os resultados parciais da pesquisa até agora realizada, e visando colaborar no conhecimento dos processos de precarização em curso, temos observado, grosso modo, a existência de dois grupos de trabalhadores nos aplicativos de transporte:

1) Sujeitos com qualificação técnico-científica e formação em nível médio ou superior (engenheiros, administradores, contadores, entre outros). Esses trabalhadores exerciam atividades com remuneração maior e possuíam formalização da sua relação de trabalho, usufruindo do sistema de garantias sociais (como descanso semanal, férias, $13^{\circ}$ Salário, adicional noturno). Ao perderem seus empregos, encontraram a oportunidade de conseguir alguma renda como motoristas nas plataformas. Neste processo de precarização, estes trabalhadores perderam parte da renda e das garantias e proteções trabalhistas e aumentaram suas jornadas de trabalho.

2) Sujeitos que tradicionalmente estavam ligados às atividades do circuito inferior da economia urbana, ou seja, trabalhadores com poucos anos de estudo e baixa qualificação técnico-científica ou profissional. Esses trabalhadores já estavam habituados às ocupações temporárias e atividades diversas e provisórias ("bicos" e "viração"29") e apenas eventualmente tinham acesso à formalização da relação de trabalho e às garantias sociais. Nem todos passaram por processos de informalização, embora possam ter sofrido diminuição da renda e aumento da jornada de trabalho.

Essa distinção entre duas categorias de motoristas é analítica e não visa generalizar os sujeitos que compõem o imenso exército de trabalhadores nas plataformas digitais Uber, 99 e Cabify, além das diversas empresas de entrega de comida e objetos que as sucederam (Glovo, Loggi, Rappi, UberEats, Ifood e 99 Food). As plataformas apresentam-se a esses trabalhadores como uma alternativa ao desemprego no Brasil, aliada à necessidade de dinheiro imediato para o pagamento de despesas fixas, como aluguel, alimentação, energia elétrica e água.

Para os dois grupos, as necessidades ligadas à reprodução material da vida se sobrepõem à racionalidade do cálculo de ganhos e custos do trabalho nas plataformas, pois, sem proteção estatal e garantias salariais mínimas, é preciso que o motorista trabalhe o número de horas necessário à sua sobrevivência. Reproduz-se uma lógica de aprisionamento à pobreza, a despeito das fábulas da psicoesfera do empreendedorismo, que traz em si uma ideia irrealizável de progresso material.

Essa situação impulsiona a manifestação da criatividade visando obter ganhos extras ou ampliando a circulação das pequenas quantias que delimitam a economia popular. Esse sentido de sobrevivência dos trabalhadores confere ao circuito inferior a condição de um abrigo ${ }^{30}$ no qual se compartilham novas formas de solidariedade em meio à escassez. Temos observado diversas táticas utilizadas por estes motoristas a partir das brechas na gestão algorítmica a que estão submetidos.

\footnotetext{
${ }^{29}$ As táticas dos trabalhadores menos qualificados são conhecidas como "bicos" ou "viração", duas categorias nativas. A "viração" foi analisada por Ribeiro (2005, p. 421) como a capacidade de adaptação dos sujeitos pobres às contingências dos lugares onde vivem, assumindo atividades provisórias, mutantes, intermitentes e que exigem pouca qualificação.

${ }^{30}$ Trata-se, aqui, de um diálogo entre as noções de "território como abrigo" e "território como recurso", propostas por Gottmann, 1975.
} 
Trabalho precário, espaço precário: as plataformas digitais de transporte e os circuitos...

Entra elas, pode-se destacar o oferecimento de viagens particulares, por meio da entrega de cartões de contato com o número do telefone pessoal e a negociação do preço entre motorista e passageiro. Nesse processo, o motorista rompe a impessoalidade do aplicativo e estabelece uma relação de proximidade que o isenta do pagamento da taxa de serviço às plataformas (entre $20 \%$ e $40 \%$ do preço da viagem). Ao mesmo tempo, o motorista utiliza a plataforma para calcular o preço das suas viagens particulares, simulando o trajeto que será percorrido. Essa tática mescla a confiança no preço estipulado pela plataforma com a confiança do contato interpessoal. Mesmo que não seja utilizada nesses casos, a plataforma se torna um padrão do preço das viagens e reforça, indiretamente, sua validação social.

Há também relatos de motoristas que dirigem um veículo emprestado por algum familiar ou amigo, sem o pagamento de aluguel, porém arcando com as despesas de manutenção e desgaste. Em outros relatos, observou-se que o contrato de locação do veículo não era feito com uma grande empresa (como Localiza, Hertz ou Movida), mas com outro motorista que se tornou proprietário de dois ou três veículos e modificou sua atuação econômica. Não havia, em geral, um contrato formal entre as partes, mas um acordo verbal apoiado em relações de confiança e proximidade.

Outra tática relatada foi o empréstimo do veículo para algum amigo ou familiar que teve o seu carro furtado. O revezamento do veículo entre mais de um motorista também é comum, como o jovem que relatou que ele e seu pai dirigiam o mesmo carro: enquanto seu pai dirigia durante o dia, ele descansava. À noite, o filho dirigia e o pai descansava. Também se observou o empréstimo de dinheiro para pagamento de multas de trânsito e consertos emergenciais no veículo. Há, ainda, táticas mais sofisticadas para driblar o controle algorítmico das plataformas, como os motoristas que manipulavam sua localização pelo GPS com o objetivo de conseguir corridas com valores maiores ou, ainda, utilizavam o cadastro de um terceiro quando estavam suspensos pela plataforma ${ }^{31}$.

Notou-se, ainda, a cooperação mútua e a criação de redes de amparo entre os motoristas, com destaque para os grupos virtuais por WhatsApp, Telegram ou Facebook. Aqui, observou-se outra característica distintiva dos sujeitos trabalhadores do circuito inferior: a comunicação impõe limites à eficácia completa da informação hegemônica controlada pelas plataformas digitais.

As redes sociais virtuais permitem o compartilhamento da localização em tempo real do smartphone por até 8 horas. Todos os motoristas de um grupo compartilhavam suas localizações e caso algum tenha atividade incomum, como a permanência excessiva em uma localização fixa, os outros se articulam para averiguar sua segurança, por mensagens de texto, ligações ou dirigindo-se ao local. Essa forma de organização permite também a troca de experiências, como as áreas a serem evitadas ou aquelas com maior demanda de corridas, e a organização de protestos contra as empresas, como o "Uber OFF", articulado por meio de grupos pelo WhatsApp, após mudanças unilaterais das tarifas e taxas pela corporação ${ }^{32}$.

\footnotetext{
${ }^{31}$ Essas táticas remetem à discussão proposta por Gibson-Graham (2006, pp. 70-71) que destacam as atividades não remuneradas, legais ou ilegais, que sustentam as relações sociais, como os empréstimos, trabalho não pago, barganhas, cooperativismo, pagamento alternativo, voluntariado entre outros.

${ }^{32}$ Uber Off foi o nome dado a uma paralisação promovida por motoristas da Uber em diversas cidades pelo mundo, em 8 de maio de 2019. Foi organizada pelo WhatsApp, e reivindicava melhores condições de trabalho e mudanças na política de cobrança de taxas.
} 


\section{O trabalho precário e o espaço precário dos motoristas das plataformas digitais no Aeroporto de Confins (MG)}

Com o objetivo de aprofundar a análise de algumas das situações observadas na pesquisa, nos dedicamos à correlação entre o espaço e o trabalho precário dos motoristas de aplicativo no Aeroporto de Confins. Inaugurado em 1984, o Aeroporto passou por ampliações recentes que aumentaram sua centralidade no sistema aeroportuário nacional. Consolidou-se, em consequência, como uma das principais áreas de demanda por viagens na Região Metropolitana de Belo Horizonte.

O Aeroporto de Confins tornou-se uma área disputada pelas empresas de aplicativo, particularmente a Uber, fato que se repete nos demais aeroportos nacionais e internacionais. As atividades modernas, como os aeroportos, solicitam outras modernizações ${ }^{33}$, como as plataformas de transporte, e novas cooperações e conflitos se estabeleceram na área.

Os principais fluxos de passageiros do Aeroporto têm origem e destino no município de Belo Horizonte, à $40 \mathrm{~km}$ de distância. Os motoristas que levam passageiros a este Aeroporto esperam, durante horas, na expectativa de uma corrida de retorno. Conforme foi possível observar durante visitas ao local, o número de veículos na "fila virtual" de espera é normalmente superior a 100, o que significa que eles aguardam entre 6 a 8 horas, em média, para realizar uma viagem. Este tempo de espera não é remunerado pelas plataformas. Além disso, a jornada é desprovida de apoios e infraestruturas, pois o corolário geográfico desse trabalho precário é, igualmente, um local precário.

Frente à ausência de estruturas e diante da necessidade de estar nos arredores do Aeroporto, os motoristas desenvolveram táticas próprias, dentre as quais destacam-se três i) a utilização dos acostamentos da via expressa Linha Verde como estacionamento provisório; ii) a transformação de ruas próximas em locais de estacionamento e de venda de alimentos e água; iii) a transformação de antigos pontos comerciais em locais de apoio.

A primeira e a segunda estratégias foram as primeiras a se constituírem, junto com a chegada da Uber ao Aeroporto, em 2014, e têm caráter mais espontâneo. Os motoristas utilizavam o sistema viário das áreas próximas ao Aeroporto como locais de permanência, o que é ilegal, como indicam as placas de sinalização (Figura 3). Os relatos indicam que a fiscalização e as multas eram constantes, tanto no acostamento da via expressa Linha Verde quanto nas ruas que circundam um hotel próximo. A longa permanência nesses locais levou à criação de pequenas atividades econômicas para satisfazer as necessidades dos motoristas, como a venda de água e alimentos em tendas adaptadas nos bagageiros dos veículos. A venda desses produtos é realizada por motoristas que também esperavam na "fila virtual" do Aeroporto.

\footnotetext{
${ }^{33}$ Conforme a correlação entre modernidades defendida por Silveira, 2013, p. 65.
} 
Trabalho precário, espaço precário: as plataformas digitais de transporte e os circuitos...

Figura 3. Áreas de espera criadas pelos motoristas de aplicativo próximas ao Aeroporto de Confins (MG)
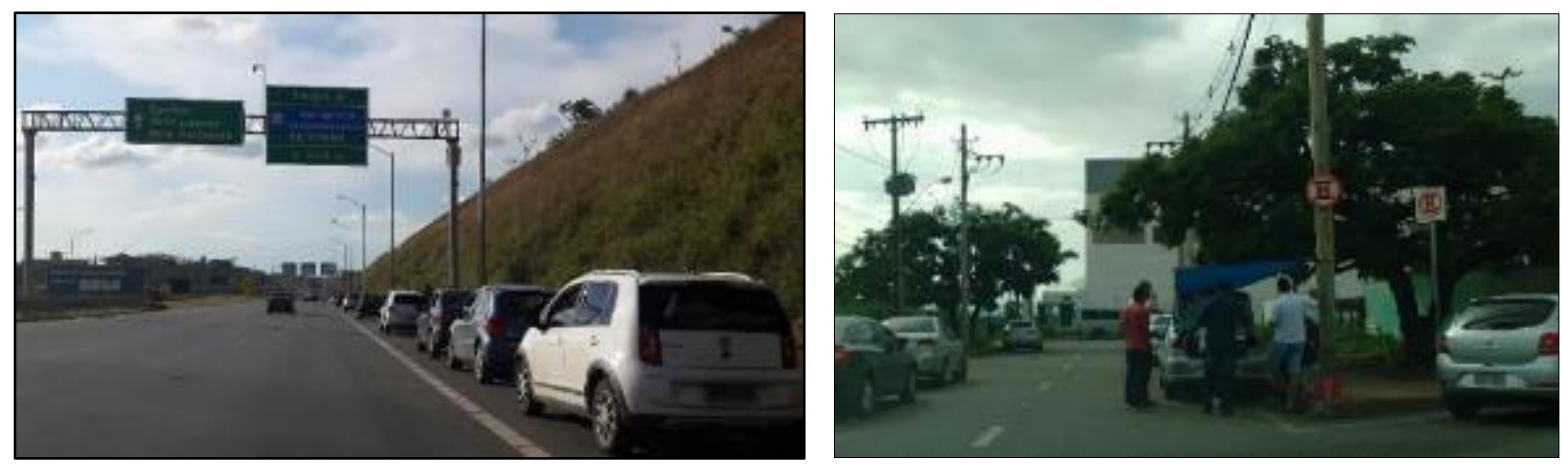

Fonte: Autoria própria, em 16/10/2018 e 16/12/2017, respectivamente.

Nota: Na imagem à esquerda, veículos estacionados na via expressa Linha Verde; à direita, carros estacionados em zona proibida nas ruas próximas ao Aeroporto, com destaque para a tenda azul destinada à venda de alimentos e bebidas no bagageiro de um dos veículos.

Diante dessas situações de extrema precariedade e da ação ostensiva da fiscalização estatal e das multas de trânsito, surge a terceira estratégia: um motorista teve a iniciativa de alugar um galpão distante $10 \mathrm{~km}$ do Aeroporto para transformá-lo em um "ponto de apoio" aos demais motoristas. A área era originalmente chamada Espaço Usina e foi renomeada como Espaço Pop. Apesar de sugestivo, o motorista responsável pelo estabelecimento informou que não havia vínculos com a empresa 99, anteriormente 99 $\mathrm{Pop}^{34}$ (Figura 4).

No Espaço Pop, buscou-se suprir a ausência de infraestruturas fundamentais durante as horas de espera: restaurante, lanchonete, banheiros, lava jato e dormitórios improvisados que eram alugados aos motoristas. Na recepção havia tomadas elétricas e Internet wireless, duas necessidades básicas dos motoristas, pois o smartphone é um instrumento de trabalho utilizado em tempo integral e a permanência na "fila virtual" depende dele. Há, ainda, televisão, videogames e mesa de sinuca, o que permitia formas de lazer e entretenimento e possibilita o contato pessoal entre os motoristas.

Embora alguns serviços fossem gratuitos (como o uso do banheiro), a alimentação e a utilização dos dormitórios incluem gastos que elevam os custos fixos que recaem sobre esses trabalhadores. Por isso, diversos motoristas aguardam dentro de seus veículos, beneficiando-se da segurança oferecida pelo local, evitando realizar novas despesas e consumos no Espaço Pop. Esse tipo de "repouso" revela outra dimensão da precariedade da situação na qual os motoristas esperavam por uma chamada com origem no Aeroporto.

\footnotetext{
${ }^{34}$ As entrevistas foram realizadas com motoristas que utilizavam o Espaço Pop e com o responsável por gerenciálo. Alguns motoristas tiveram receio de conversar conosco, pois temiam que fossemos funcionários da Uber "à paisana", fato que simboliza a relação que os motoristas possuem com a empresa.
} 
Figura 4. Espaço Pop, ponto de apoio aos motoristas do Aeroporto de Confins (MG)
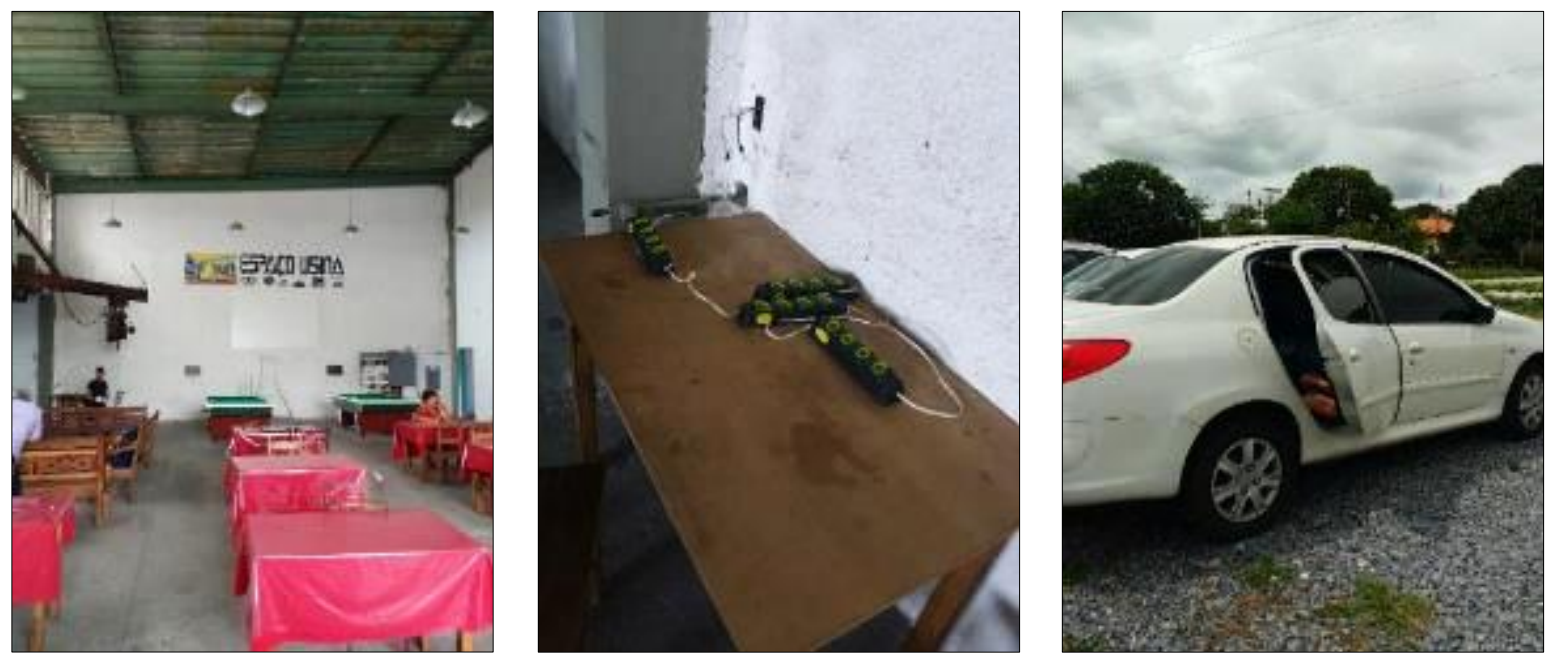

Fonte: Autoria própria, em 16/12/2017.

Nota: Da esquerda para a direita: área interna do Espaço Pop, com sofás, mesas de refeições e mesas de sinuca; as adaptações na rede elétrica para o carregamento dos smartphones; um motorista repousando dentro de seu veículo, no estacionamento do Espaço Pop.

Em abril de 2019, após negociações entre a Uber e o operador privado do Aeroporto (BH Airport), uma área dentro do estacionamento do Aeroporto foi reservada aos motoristas da empresa. O tempo de espera por uma viagem de retorno continua, em média, superior a 6 horas e os motoristas aguardam, dentro de seus carros, na centenária "fila virtual". Não havia mais riscos de multas de trânsito, mas os trabalhadores seguiam expostos às condições climáticas, pois a Uber não investiu na criação de infraestruturas básicas de apoio aos motoristas no Aeroporto. Logo o que aparentava ser uma melhoria das condições ambientais de trabalho, não se realizou, a não ser pontualmente, como na possibilidade de utilização dos sanitários dentro do Aeroporto. Além disso, os motoristas, condicionados pelo GeoFencing à área exclusiva do estacionamento, não podem sair para acessar as formas mais baratas de alimentação que haviam sido desenvolvidas nas ruas próximas ou no Espaço Pop. Seu tempo de espera é condicionado aos limites do cercamento geográfico definido pela plataforma, que, todavia, não remunera os trabalhadores por esse tempo sob seu controle.

Motivadas pela demanda concentrada no Aeroporto, diferentes combinações entre trabalho e espaço precário se concretizam. No território, a modernidade da Uber mostra-se dependente do trabalho precário e dos locais improvisados. A plataforma e o algoritmo são programados com uma perspectiva alienadora dos sujeitos e dos lugares, na medida em que lhes retiram possibilidades de autonomia objetivando o uso corporativo do território e o controle subordinado dos motoristas. 
Trabalho precário, espaço precário: as plataformas digitais de transporte e os circuitos...

\section{Considerações finais}

Como procurou-se mostrar, o avanço das plataformas digitais impõe mudanças substantivas nas formas históricas de organização da vida social e dos territórios, especialmente a partir de um novo patamar que empresas globais como Uber, 99 e Cabify representam no ramo dos transportes. Isso não significa, todavia, ignorar o processo histórico e a vitalidade de categorias analíticas nas diversas ciências sociais, em particular a Geografia, como se procurou enfatizar. De fato, a digitalização da ação não abdica do território como uma plataforma, pelo contrário: o espaço se torna um fator produtivo essencial às empresas globais de informação.

Quanto ao mito da liberdade de escolha dos motoristas, ele não resiste ao fato de que a maioria deles possui a escolha limitada ao duopólio Uber-99 na maior parte do Brasil. Seus veículos são simples e envelhecidos demais para que possam trabalhar com a Cabify, que por sua vez mantém-se restrita a zonas e classes de rendas mais elevadas em poucas metrópoles brasileiras. No mais, a avaliação e a classificação dos motoristas os submetem a novos controles onipresentes e unilaterais, como se evidenciou na avaliação de frenagens e acelerações. São raras, quando existem, as possibilidades de defesa desses trabalhadores contra uma máavaliação, uma advertência ou o bloqueio pela plataforma.

Como características constitutivas do chamado "trabalho uberizado", pode-se mencionar a transferência de riscos e custos da empresa para uma multidão de trabalhadores, o deslocamento do estatuto de trabalhador para o de microempreendedor e a prevalência do discurso da meritocracia. Os motoristas têm sua renda diminuída pois arcam com os custos inerentes à atividade laboral: manutenção e depreciação do carro e do smartphone, seguro do veículo e combustível. As taxas cobradas pelas plataformas, por sua vez, são mecanismos de "vampirização" do dinheiro do trabalhador e da economia locais.

Além do empobrecimento direto de motoristas que anteriormente possuíam empregos formais, há um empobrecimento relativo que deriva da combinação de três custos que recaem sobre eles: i) a criação de taxas dinâmicas pelas corporações, impedindo que o trabalhador calcule seus ganhos e programe suas metas de trabalho; ii) a oligopolização do setor, que leva ao aumento da escala de prestação de serviço e, consequentemente, ao congelamento ou redução dos preços das viagens; iii) o aumento dos custos fixos, particularmente do preço dos combustíveis, que são absorvidos pelos trabalhadores, além dos demais custos derivados do desgaste progressivo dos instrumentos de trabalho, que necessitam ser substituídos (caso dos smatphones) ou consertados (veículos).

Acredita-se que a teoria dos circuitos da economia urbana pode contribuir para aprofundar as análises e debates sobre as formas de organização das corporações de transporte por aplicativo e o uso que fazem do território brasileiro, com destaque para o papel central das cidades. Com objetos como smartphones, os nexos informacionais entre os circuitos superior e inferior se multiplicam, a despeito da hierarquia dos agentes e das atividades envolvidos. Esta teoria permite compreender a atualidade dessas corporações de plataforma, sem, contudo, negar sua constituição histórica enquanto empresas hegemônicas em seu setor de atuação. Evita-se, dessa maneira, as armadilhas ideológicas de que estaríamos vivendo uma "nova economia do compartilhamento", com suas "empresas disruptivas" e seus "ecossistemas em nuvem". No mais, esta teoria coloca o território no primeiro plano do nível analítico, evitando, igualmente 
análises simplistas que tratam as empresas em si mesmas, ou um reino digital apartado da materialidade da vida social.

Por isso, enfatizamos que o trabalho precário encontra seu correlato no espaço precário, fazendo com que as jornadas de trabalho sejam cumulativamente insalubres: longas na sua duração e desconfortáveis na sua ambiência, dada a inexistência de condições de apoio mínimas, como acesso a água, sanitários, locais de descanso, abrigo e alimentação. A situação vivida pelos motoristas que trabalham no Aeroporto de Confins revela que a modernidade, no Brasil, convive organicamente com formas de organização do trabalho e do território que atentam à dignidade da vida e da atividade laboral.

Não obstante, esse empobrecimento é também das economias locais e regionais, pois parte do dinheiro que circulava entre os agentes locais (como taxistas e sistemas de transporte público) acaba sendo drenada, pelas taxas, às suas matrizes estrangeiras, caso de São Francisco (Uber), Beijing (99) e Madri (Cabify). Esse tema é fundamental para a compreensão das relações assimétricas entre os países na atual divisão internacional do trabalho. Ademais, como utilizam de manobras jurídicas para se definirem como "empresas de tecnologia" e não "empresas de transporte", tais corporações encontram brechas para o pagamento de taxas e impostos menores ${ }^{35}$. Ao mesmo tempo, a ação dessas corporações é cada vez mais multissetorial e financeirizada.

Finalmente, pode-se observar que se articulam formas de resistência, ainda que iniciais. Casos como o dos protestos "Uber Off", organizados por motoristas de diversas cidades do mundo e as paralisações de entregadores por aplicativo em países como a Argentina e o Brasil ${ }^{36}$ revelam que se dissemina uma percepção das relações de submissão a que estes trabalhadores estão subjugados. No mais, algumas decisões judiciais enquadram as plataformas dentro de normas trabalhistas, em vários países ${ }^{37}$. Logo, acredita-se que os processos analisados exigem um acompanhamento constante das diversas ciências sociais, pois indicam mudanças constantes, embora qualitativamente distintas nas diversas formações socioespaciais.

\section{Agradecimento}

Esta pesquisa contou com o apoio do Ministério Público do Trabalho - $3^{\mathrm{a}}$ Região, por meio de convênio firmado com a UFMG (ref. 078/19-00), projeto de pesquisa "Plataformas digitais de transporte privado por aplicativo e novas relações de trabalho em Belo Horizonte (MG)."

\footnotetext{
${ }^{35}$ Em direção oposta ao que ocorreu no Brasil, o Tribunal de Justiça da União Europeia considerou a Uber uma "empresa de transporte", e não uma "plataforma digital", como ela alegava. Isso permitiu que as autoridades nacionais, regionais e municipais pudessem exigir licenças como aquelas requeridas aos profissionais de táxi e modificou o enquadramento da empresa para fins de cobrança de impostos e taxas. Disponível em: Sentencia del Tribunal de Justicia (Gran Sala), En el asunto $\mathrm{N}^{\circ} \mathrm{C}-434 / 15$, Asociación Profesional Elite Taxi contra Uber Systems Spain SL, de 20 de dezembro de 2017. Disponível em: https://eur-lex.europa.eu/legalcontent/ES/TXT/HTML/?uri=CELEX:62015CJ0434\&from=EN. Acesso em 15/02/2018.

${ }^{36}$ Paula Soprana, Entregadores organizam paralisação e movimento chega a capitais latinas, Folha de São Paulo, 28/06/2020. Disponível em: <https://www1.folha.uol.com.br/mercado/2020/06/entregadores-organizamparalisacao-e-movimento-chega-a-capitais-latinas.shtml> Acesso em: 09 de junho de 2020.

${ }^{37}$ Decisão judicial do Central London Employment Tribunal (case n ${ }^{\circ}$ 2202550/2015, Mr Y Aslam; Mr. J Farrar v. Uber B.V; Uber London Ltd; Uber Britannia Ltd.) e Decisão administrativa da California Labor Comission (case no 11-46739 EK, June 3, 2015, Barbara Ann Berwick v. Uber Technologies Inc.).
} 
Trabalho precário, espaço precário: as plataformas digitais de transporte e os circuitos...

\section{Referências bibliográficas}

ABILIO, Ludmila Costhek. Uberização do trabalho: subsunção real da viração. Passa Palavra. $<$ http://passapalavra.info/2017/02/110685>. [21 de agosto de 2020].

ANTUNES, Ricardo. O privilégio da servidão: o novo proletariado de serviços na era digital. $1^{\mathrm{a}}$ ed. São Paulo: Boitempo, 2018. 325p.

BOZZI, Fábio. Da psicoesfera do empreendedorismo à precarização contemporânea do trabalho. (Monografia, Graduação em Geografia). Universidade Federal de Minas Gerais, Belo Horizonte: 2019.

CASTANHEIRA, Gabriel Rocha. Território nacional e precarização do trabalho: a Uber e o espaço enquanto dado ativo na Região Metropolitana de Belo Horizonte. [En Línea]. (Monografia - Graduação em Geografia). Universidade Federal de Minas Gerais, Belo Horizonte: 2019. 126p. <https://continenteufmg.com/teses-dissertacoes-tccs $>$. [21 de agosto de 2020].

CASTANHEIRA, Gabriel Rocha; DUARTE, Leandro Ribeiro. Uberização e a ação política da Uber: A precarização como norma e o uso do território como recurso. In: RENA, Natacha; FREITAS, Daniel; SÁ, Ana Isabel; BRANDÃO, Marcela. (Org.). Anais do II Seminário Internacional Urbanismo Biopolítico. [En Línea]. Belo Horizonte: Associação Imagem Comunitária, 2019, $\quad$ v. $\quad 1, \quad$ p. 1066-1089. $<$ https://wiki.indisciplinar.com/webdav/seminarios/0605_FN1_ANAIS20UB_2019_FN5.pdf $>$. [8 de junho de 2020].

CATAIA, Márcio; SILVA, Silvana. Considerações sobre a teoria dos dois circuitos da economia urbana na atualidade. [En Línea]. Campinas-SP: Boletim Campineiro de Geografia, v. 3, n. 1, 2013, p. 55-75. $\quad<$ http://agbcampinas.com.br/bcg/index.php/boletimcampineiro/article/view/111>. [08 de junho de 2020].

CARDON, Dominique; CASILLI, Antonio A. Qu'est-ce que le digital labor? Bry-sur-Marne: INA Éditions, 2015, 104p.

DANTAS, Marcos. Capitalismo na era das redes: trabalho, informação e valor no ciclo da comunicação produtiva. In: LASTRES, Helena; ALBAGLI, Sarita (Org.). Informação e globalização na Era do Conhecimento. Rio de Janeiro: Campus, 1999, p. 216-261.

DUARTE, Leandro. $O$ território como recurso e a informação como estratégia das corporações de transporte por aplicativo no Brasil. [En Línea]. (Monografia - Graduação em Geografia). Universidade Federal de Minas Gerais, Belo Horizonte: 2019. 117p. $<$ https://continenteufmg.com/teses-dissertacoes-tccs $>$. [21 de agosto de 2020].

GIBSON-GRAHAM, J. K. A postcapitalist politics. Minnesota: University of Minnesota Press, 2006. 276p. 
GOTTMANN, Jean. The evolution of the concept of territory. Social Science Information. [En

Línea]. Vol. $\quad 14, \quad$ n. $\quad 3, \quad 1975, \quad$ p. $<$ https://journals.sagepub.com/doi/10.1177/053901847501400302>. [07 de junho de 2020].

HARDT, Michael; NEGRI, Antonio. Empire. Cambridge: Harvard University Press, 2000. $501 \mathrm{p}$.

HARVEY, David. The condition of postmodernity: An Enquiry into the origins of cultural change. Cambridge: Oxford: Blackwell Publishers, 1990. 378p.

LOJKINE, Jean. La révolution informationnelle. Paris: Presses Universitaires de France, 1992.

MONTENEGRO, Marina Regitz. Globalização, trabalho e pobreza no Brasil metropolitano. O circuito inferior da economia urbana em São Paulo, Brasília, Fortaleza e Belém. [En Línea]. Tese (Doutorado em Geografia Humana). Universidade de São Paulo, São Paulo: 2012. $<$ https://teses.usp.br/teses/disponiveis/8/8136/tde-12062012-133347/pt-br.php >. [15 de agosto de 2020].

OITAVEN, Juliana Carreiro Corbal; CARELLI, Rodrigo de Lacerda; CASAGRANDE, Cássio Luís. Empresas de Transporte, Plataformas Digitais e a Relação de Emprego: Um estudo do trabalho subordinado sob aplicativos. [En Línea]. Brasília: Movimento; Ministério Público do Trabalho, 2018, 248p. <https://csb.org.br/wp-content/uploads/2019/01/CONAFRET_WEBcompressed.pdf $>$. [21 de agosto de 2020].

POCHMANN, Márcio. [Entrevista concedida a] André Antunes. A uberização leva à intensificação do trabalho e da competição entre os trabalhadores. Escola Politécnica de Saúde Joaquim Venâncio/Fiocruz. [En Línea]. Publicado em 09 de novembro de 2016. $<$ http://www.epsjv.fiocruz.br/noticias/entrevista/a-uberizacao-leva-a-intensificacao-dotrabalho-e-da-competicao-entre-os>. [15 de agosto de 2020].

RIBEIRO, Ana Clara Torres. Sociabilidade, hoje: leitura da experiência urbana. Caderno CRH. [En Línea]. Salvador: Universidade Federal da Bahia. v. 18, n. 45, 2005, pp. 411-422. Disponível em: <https://portalseer.ufba.br/index.php/crh/article/view/18535/11911>. [08 de junho de 2020].

ROSENBLAT, Alex. UBERLAND: how algorithms are rewriting the rules of work. Califórnia: University of California Press, 2018. 338p.

SANTOS, Milton. L'espace partagé. Les deux circuits de l'économie urbaine des pays sousdéveloppés. Paris: M-Th. Génin Librairies Techniques, 1975.

SANTOS, Milton. Técnica, Espaço, Tempo: globalização e meio técnico- científicoinformacional. São Paulo: HUCITEC, 1994.

SANTOS, Milton. A natureza do espaço: técnica e tempo, razão e emoção. São Paulo: HUCITEC, 1996.

SANTOS, Milton. Por uma outra globalização: do pensamento único à consciência universal. Rio de Janeiro: Editora Record, 2000. 
Trabalho precário, espaço precário: as plataformas digitais de transporte e os circuitos...

SILVA, Adriana Bernardes da. São Paulo, produção de informações e reorganização do território brasileiro. Tese (Doutorado em Geografia Humana). Universidade de São Paulo, São Paulo: 2001. <https://www.ige.unicamp.br/geoplan/professores/adriana-bernardes/textos/>. [15 de agosto de 2020].

SILVEIRA, María Laura. Da pobreza estrutural à resistência: Pensando os circuitos da economia urbana. Revista Ciência Geográfica. [En Línea]. Bauru, Vol. XVII. 2013. $<\mathrm{http}$ :/www.agbbauru.org.br/publicacoes/revista/anoXVII_1/agb_xvii1_versao_internet/agb_ 05_jandez2013.pdf $>$. [21 de agosto de 2019].

SILVEIRA, María Laura. Modernização contemporânea e nova constituição dos circuitos da economia urbana. Geousp - Espaço e Tempo. [En línea]. São Paulo: Universidade de São Paulo, v. 19, n. 2, p. 246-262. 2015. <http://www.revistas.usp.br/geousp/article/view/102778>. [15 de agosto de 2020].

SLEE, Tom. What's yours is mine: against the sharing economy. New York: OR Books, 2015.

SRNICEK, Nick. Platform Capitalism. Cambridge: Polity Press, 2016.

STONE, Brad. The Upstarts. How Uber, Airbnb, and the killer companies of the Silicon Valley are changing the world. New York: Little, Brown and Company, 2017.

TOZI, Fábio. Uso do território brasileiro por empresas globais de transporte por aplicativos: as estratégias de ação da Uber e as tensões advindas das resistências locais e regionais. Anais do XII ENANPEGE. [En Línea]. Dourados: UFGD, v. 1, 2017a, p. 10270-10281. $<$ http://www.enanpege.ggf.br/2017/anais/>. [20 de agosto de 2020].

TOZI, Fábio. Uma compreensão sistemática do fenômeno da pirataria a partir da teoria dos circuitos da economia urbana: um exercício teórico-metodológico. In: DANTAS, Aldo; ARROYO, Mónica; CATAIA, Márcio. (Org.). Dos circuitos da economia urbana aos circuitos espaciais de produção: um diálogo com a teoria de Milton Santos. Natal: Sebo Vermelho, 2017 , p. 387-415.

TOZI, Fábio. As novas tecnologias da informação como suporte à ação territorial das empresas de transporte por aplicativo no Brasil. In: ZAAR, Miriam; CAPEL, Horacio. (Org.). Las ciencias sociales y la edificación de una sociedad post-capitalista. [En Línea]. Barcelona: Universidad de Barcelona/Geocrítica; XV Colóquio Internacional de Geocrítica, 2018, v. 1, pp. 172-187. <http://www.ub.edu/geocrit/XV-Coloquio/Programa-XV-Coloquio.htm>. $[21 \mathrm{de}$ agosto de 2020].

TOZI, Fábio; DUARTE, Leandro. Conhecimento e controle do território: do discurso da mobilidade à geopolítica da Uber. In: RENA, Natacha; FREITAS, Daniel; SÁ, Ana Isabel; BRANDÃO, Marcela. (Org.). I Seminário Internacional Urbanismo Biopolítico. [En Línea]. Belo Horizonte: Fluxos, 2018, p. 326-346. $<$ http://seminariourbanismobiopolitico.indisciplinar.com/wp-content/uploads/2018/06/0601_Anais_Seminario-UB_FINAL_2-1.pdf $>$. [9 de junho de 2020]. 
UBER TECHNOLOGIES INC. Form S1 Registration Statement. United States Securities and Exchange Commission (2019). Estados Unidos, 11 abril de 2019. $<$ https://www.sec.gov/Archives/edgar/data/1543151/000119312519103850/d647752ds1.htm> [9 junho de 2020].

ZUBOFF, Shoshana. Big other: surveillance capitalism and the prospects of an information civilization. Journal of Information Technology. [En Línea]. 2015, 30, p. 75-89. $<$ https://ssrn.com/abstract=2594754>. [15 de junho de 2020].

Ficha bibliográfica:

TOZI, Fábio; DUARTE, Leandro Ribeiro; CASTANHEIRA, Gabriel Rocha. Trabalho precário, espaço precário: as plataformas digitais de transporte e os circuitos da economia urbana no Brasil. Ar@cne. Revista Electrónica de Recursos de Internet sobre Geografia y Ciencias Sociales. Barcelona: Universidad de Barcelona, I de marzo de 202I, vol. XXV, n 252. DOI: https://doi.org/I0.1344/ara202I.252.33968

\author{
Menú Geo Crítica
}

